\title{
Variability in behavior and production among dairy cows fed under differing levels of competition
}

\author{
R. E. Crossley, A. Harlander-Matauschek, and T. J. DeVries ${ }^{1}$ \\ Department of Animal Biosciences, University of Guelph, 50 Stone Rd. East, Guelph, ON, N1G 2W1, Canada
}

\begin{abstract}
The objective of this study was to investigate the effects of differing levels of competition for feed access on group-housed dairy cows, and on variations in behavior and productivity between individuals within each group. Eighteen lactating Holstein cows, averaging $77 \pm 20 \mathrm{~d}$ in milk with a production of $46 \pm 7 \mathrm{~kg} / \mathrm{d}$ at the start of the trial, were divided into subgroups of 3 and fed a total mixed ration $3 \times / \mathrm{d}$. Groups were exposed to each of 3 competition levels: high (3 cows: 1 feed bin), moderate (3 cows:2 feed bins), and low (3 cows:3 feed bins). Treatments were assigned in random order according to a modified Latin-square design, and each was applied for $10 \mathrm{~d}$. Using an automated feed intake system, feeding behavior data (dry matter intake, feeding time, feeding rate, and meal patterns) were recorded for each cow on d 6 to 10 of each treatment period. Additional behavioral [sorting, rumination, competitive interactions (replacements), lying time] and production (milk yield and components) data were collected. Greater competition resulted in a reduction in feeding time (low $=202.6$, moderate $=194.9$, high $=183.6 \mathrm{~min} / \mathrm{d} ; \mathrm{SE}=8.84)$, and an increased rate of feed intake (low $=0.16$, moderate $=0.18$, high $=0.20$ $\mathrm{kg}$ of dry matter $/ \mathrm{min} ; \mathrm{SE}=0.01$ ), especially following fresh feed delivery and milking. Dry matter intake was similar across treatments (average of $29.1 \mathrm{~kg} / \mathrm{d}$ ). Meal length increased under high competition (low $=37.0$, moderate $=36.6$, high $=47.3 \mathrm{~min} / \mathrm{meal} ; \mathrm{SE}=5.05$ ) due to greater non-feeding time within meals, which was approximately twice as long under high competition $($ low $=10.0$, moderate $=10.8$, high $=20.3 \mathrm{~min} /$ meal; $\mathrm{SE}=3.24$ ). Daily lying time (low $=10.2$, moderate $=10.2$, high $=9.5 \mathrm{~h} / \mathrm{d} ; \mathrm{SE}=0.51)$ and milk protein yield $($ low $=1.41, \bmod =1.42, \operatorname{high}=1.36 \mathrm{~kg} / \mathrm{d} ; \mathrm{SE}$ $=0.05$ ) were reduced under high competition. Analysis of individual within-group variability, calculated as the
\end{abstract}

Received October 4, 2016

Accepted January 27, 2017.

${ }^{1}$ Corresponding author: tdevries@uoguelph.ca daily standard deviation of each group, averaged across 5 recording days, revealed greater variability in feeding time, feeding rate, meal length, non-feeding time within meals, milk yield, milk fat composition (\%), and milk fat component yield $(\mathrm{kg} / \mathrm{d})$ under high competition. These results suggest that at elevated competition levels, cows modify their feeding behavior to consume feed in a shorter period and devote a large portion of their mealtime toward waiting to gain feed access, resulting in reduced daily lying time. Furthermore, meal patterns and milk production vary greatly within groups of cows at high levels of competition for feed access.

Key words: dairy cow, feeding behavior, competition, meal patterns, milk production

\section{INTRODUCTION}

Dairy cows experience the greatest motivation to feed following the delivery of fresh feed and, to a lesser extent, upon return from milking (DeVries and von Keyserlingk, 2005; King et al., 2016). However, when space at the feed bunk is limited, particularly at these times of high bunk attendance, individual cows must compete for feed access. Competition for resources such as feed leads to greater social pressure (Nielsen, 1999) and altered feeding behavior, such as reduced feeding time (Huzzey et al., 2006; Proudfoot et al., 2009), increased feeding rate (Olofsson, 1999; Hosseinkhani et al., 2008), and greater idle standing time (Huzzey et al., 2006). Higher frequency of displacement from the feeding area has also been demonstrated under increased competition for feed access, particularly for subordinate cows (Huzzey et al., 2006; Val-Laillet et al., 2008; Proudfoot et al., 2009). These alterations of feeding behavior in competitive environments may lead to abnormal intake and meal patterns, as well as greater stress on the hoof, resulting in health problems such as subacute ruminal acidosis (Shaver, 2002) and increased lameness (Cook et al., 2004). The productivity of individual cows may also be affected by such changes in feeding behavior, because milk production has been correlated with feeding time and DMI (Dado and Allen, 1994; Shabi et al., 2005). 
Subordinate cows have demonstrated a greater stress response to feeding in the company of higher-ranked neighboring cows (Hetti Arachchige et al., 2014), and a tendency to sacrifice feed quality to avoid feeding in proximity to a more dominant individual (Rioja-Lang et al., 2009). This indicates that feeding conditions can impose great social stress on subordinate cows, which have been observed to deviate from preferred peak feeding times associated with fresh feed delivery when under competitive pressure (Olofsson, 1999). In these situations, individuals may consume a diet that is different from that intended, because feed sorting results in altered feed composition further from feed delivery times (Leonardi and Armentano, 2003). Hosseinkhani et al. (2008) studied the effects of feed bunk competition on feed sorting by close-up prepartum cows and found a tendency for competition to affect the sorting of medium particles: competitively fed cows displayed less sorting of medium particles than non-competitively fed cows shortly after feed delivery. However, those researchers compared only non-competitively and competitively fed cows and did not consider to what extent the degree of competition could affect sorting behavior. In addition, they looked at close-up cows fed a diet with a higher proportion of forage compared with a lactating cow diet; such a diet could be less easily sorted than a lower-forage lactating cow ration (DeVries et al., 2007).

A common factor in most studies of feeding competition is that subordinate cows are particularly affected by increased levels of competition (DeVries et al., 2004; Huzzey et al., 2006; Val-Laillet et al., 2008). Depending on grouping strategy, individual cows in group-housed systems can differ based on their age, parity, stage of lactation, production level, and BW, all of which may influence their relative social position and contribute to their success in competitive interactions. Poor success in gaining feed access in competitive situations can act as a source of physiological stress, with negative consequences for an individual cow's welfare (Huzzey et al., 2012b; Hetti Arachchige et al., 2014). Although these studies have discussed differences between dominant and subordinate cows, they have not investigated how individual variability among all cows in the group may affect respective feed intake, meal patterns, and time allocated to other behaviors (e.g., ruminating and lying down).

The primary objective of this study was to investigate the effect of differing levels of competition for feed access on the behavior and productivity of group-housed dairy cows. The secondary objective was to determine the effect of competition on variability in behavior patterns and productivity between individuals within the group. We hypothesized first that as competition increased, cows would consume their feed faster and in larger meals, reducing their ability to sort feed and their time spent ruminating and lying down, in turn negatively affecting their milk production. We also hypothesized that individuals within each group would experience more variability in patterns of behavior and productivity when under greater competition for feed access.

\section{MATERIALS AND METHODS}

\section{Animals and Housing}

Eighteen lactating Holstein dairy cows, including 5 primiparous and 13 multiparous (average parity $=3.4$ \pm 1.3 ), were chosen from the research herd at the University of Guelph, Kemptville Campus Dairy Education and Innovation Center. At enrollment in the study, subject animals were $77 \pm 20 \mathrm{DIM}$, with an average milk production of $46 \pm 7 \mathrm{~kg} / \mathrm{d}$, and a BW of $721 \pm 85$ $\mathrm{kg}$. The health status of each cow was evaluated before selection and monitored throughout the trial; no cows experienced health concerns that required removal from the study during transition, early lactation, or the study period. Each cow participated in the study for a total of $33 \mathrm{~d}$. Cows were housed in groups of 6 , in a freestall pen with 6 automated feed bins (Insentec RIC, Marknesse, the Netherlands) and 6 stalls (arranged in 2 rows, head-to-head) equipped with waterbeds (DCC Waterbeds; Advanced Comfort Technology Inc., Reedsburg, WI) and bedded with wood shavings as needed. Manure was scraped from the stalls to within reach of automatic alley scrapers during milking times. Cows had ad libitum access to water from 2 bowls in the pen. To simulate conventional milking systems, cows were milked 3 times daily at fixed times: 0800, 1400, and 2000 h; at each milking, cows were brought to a holding pen for individual milking by an automatic milking system (Lely Astronaut A3 Next; Lely Industries N.V., Maassluis, the Netherlands). No supplemental feed was supplied by the automated milking system. Once per week, cows were treated with preventative hoof spray (HealMax Spray; Agrochem Farm and Dairy Products, Saratoga Springs, NY). The use of cows and experimental procedures complied with the guidelines of the Canadian Council on Animal Care (CCAC, 2009) and were approved by the University of Guelph Animal Care Committee (Animal Use Protocol 3245).

\section{Experimental Design}

The study was conducted using 3 groups of 6 individuals. Within each group, cows were assigned to 2 subgroups of 3 individuals (for a total of 6 subgroups) that were balanced for DIM, parity, and production. 
The subgroups were exposed in a modified Latin-square design to each of 3 different competition levels: high (cows fed at a ratio of 3 cows: 1 feed bin), moderate (3 cows: 2 feed bins), and low ( 3 cows: 3 feed bins). Cows were exposed in random order to each treatment for 10 d. Sample size and power analyses were used to calculate the number of replicates (subgroups) needed (Morris, 1999) to detect a $15 \%$ level of observed difference for the primary outcome variables, including feeding behavior, DMI, and sorting. Estimates of variation for these variables (mean $\mathrm{CV}=13 \%$ ) were based on previously reported values (Hosseinkhani et al., 2008; Hart et al., 2013, 2014).

Each group of 6 cows was moved into the research pen and introduced to the feed bins $3 \mathrm{~d}$ before the start of the trial. The feed bins were programmed to allow access only to specified cows, and to record their feed intakes and behavior, as validated by Chapinal et al. (2007). During this time, each subgroup of 3 cows successfully learned to access feed from only their designated bins. The feed bins for each subgroup were then assigned their respective treatments beginning at 1400 $\mathrm{h}$ on the first day of each treatment period. The first $5 \mathrm{~d}$ served as adaptation to the treatment, and data recorded were for the last $5 \mathrm{~d}$ (d 6 to 10). Recording began each day at $1400 \mathrm{~h}$ and continued until $1359 \mathrm{~h}$ the following day. Treatments were switched in random order at the end of each recording period, and the above-mentioned procedures were repeated.

\section{Feeding Procedure}

Cows were fed a TMR according to the NRC (2001) nutrient requirements of a dairy cow producing a mean milk yield of $43 \mathrm{~kg} / \mathrm{d}$ (Table 1 ). The TMR was prepared in a mixer wagon (Jaylor 4425; Jaylor Fabricating, Orton, ON, Canada) and delivered once per day to a feed cart (Rovibec 530; Ste-Monique Co., Nicolet, QC, Canada). Supplemental grain pellets were weighed manually on a scale (model 2020; Mettler-Toledo Inc., Mississauga, ON, Canada) before being mixed into the TMR for 4 min by the feed cart. Fresh feed was provided $3 \times / \mathrm{d}$ at 0800,1400 , and $2000 \mathrm{~h}$. Freshly mixed feed was first delivered each day at $1400 \mathrm{~h}(\mathbf{F 1})$ after daily emptying of the feed bins, so $1400 \mathrm{~h}$ was designated as the start of the day for data recording. Approximately 30 to $50 \%$ of the daily feed allotment was supplied at this first feeding, and the remainder was divided between the second $(2000 \mathrm{~h} ; \mathbf{F 2})$ and third (0800 h; F3) feedings. Each day, newly mixed feed was delivered directly to the feed bins at F1, and the remainder was stored in covered containers until delivery at subsequent feedings. To allow them equal opportunity to access fresh feed, cows were denied ac-
Table 1. Ration ingredients (\% of DM) and chemical composition (\% of $\mathrm{DM}$ unless otherwise noted; mean $\pm \mathrm{SD}$ ) of the fresh experimental diet

\begin{tabular}{|c|c|}
\hline Composition & Diet \\
\hline \multicolumn{2}{|l|}{ Ingredient } \\
\hline Corn silage ${ }^{1}$ & 25.0 \\
\hline Haylage $1^{2}$ & 13.0 \\
\hline Haylage $2^{3}$ & 16.9 \\
\hline High-moisture corn & 14.2 \\
\hline Protein concentrate pellet ${ }^{4}$ & 11.3 \\
\hline Grain supplement pellet ${ }^{5}$ & 19.6 \\
\hline \multicolumn{2}{|l|}{ Chemical composition $^{6}$} \\
\hline $\mathrm{DM}(\%)$ & $53.1 \pm 1.58$ \\
\hline $\mathrm{OM}$ & $92.1 \pm 0.25$ \\
\hline $\mathrm{CP}$ & $18.3 \pm 0.30$ \\
\hline $\mathrm{ADF}$ & $22.8 \pm 1.40$ \\
\hline $\mathrm{NDF}$ & $34.9 \pm 1.12$ \\
\hline $\mathrm{NFC}$ & $38.9 \pm 1.16$ \\
\hline $\mathrm{Ca}$ & $1.0 \pm 0.06$ \\
\hline $\mathrm{P}$ & $0.5 \pm 0.01$ \\
\hline $\mathrm{NE}_{\mathrm{L}}(\mathrm{Mcal} / \mathrm{kg}$ of $\mathrm{DM})$ & $1.6 \pm 0.02$ \\
\hline
\end{tabular}

${ }^{1}$ Corn silage had a DM of $41.1 \pm 4.54 \%$ and a chemical composition (DM basis) of $7.2 \pm 0.31 \% \mathrm{CP}, 26.2 \pm 1.15 \% \mathrm{ADF}$, and $42.3 \pm 1.48 \%$ NDF.

${ }^{2}$ Haylage 1: Red clover $(95 \%)$ and orchard grass $(5 \%)$ haylage had a $\mathrm{DM}$ of $36.4 \pm 1.55 \%$ and a chemical composition (DM basis) of $22.7 \pm$ $0.56 \% \mathrm{CP}, 37.3 \pm 1.77 \% \mathrm{ADF}$, and $45.1 \pm 1.46 \% \mathrm{NDF}$.

${ }^{3}$ Haylage 2: Red clover (75\%) and timothy/orchard grass (25\%) haylage had a DM of $46.3 \pm 2.92 \%$ and a chemical composition (DM basis) of $19.7 \pm 1.06 \% \mathrm{CP}, 38.5 \pm 1.55 \% \mathrm{ADF}$, and $47.4 \pm 2.71 \% \mathrm{NDF}$. ${ }^{4}$ Supplied by Dundas Feed and Seed Ltd. (Winchester, ON, Canada), including (as is) $35-40 \%$ corn distillers, $18-33 \%$ soybean meal, $8-24 \%$ canola, $6.8 \%$ calcium carbonate, $1.5-7.5 \%$ feather meal, $2.4 \%$ salt, $2.0 \%$ sodium bicarbonate, $0-3 \%$ tallow, $0.8 \%$ dicalcium phosphate, $0.4 \%$ magnesium oxide, $0.144 \%$ trace minerals, and $0.046 \%$ vitamins.

${ }^{5}$ Supplied by Dundas Feed and Seed Ltd., including 20-40\% wheat shorts, 16-34\% soybean meal, $12-32 \%$ corn, 4-14\% corn distillers grains, $0-10 \%$ oat byproduct, $3 \%$ molasses, $2.0 \%$ dry fat, $0.6 \%$ calcium carbonate, $0.9 \%$ dicalcium phosphate, $0.3 \%$ choline chloride, $0.4 \%$ salt, $0.0084 \%$ vitamins, $0.0569 \%$ trace minerals, $1.25 \%$ pellet binder, and $0.125 \%$ flavor/attractant.

${ }^{6}$ Values were obtained from chemical analysis of TMR samples. OM $=$ $100-\%$ ash. $\mathrm{NFC}=100-(\% \mathrm{CP}+\% \mathrm{NDF}+\%$ fat $+\%$ ash $) . \mathrm{NE}_{\mathrm{L}}$ was calculated based on NRC (2001) equations.

cess to the feed bins from the start of each milking until the last cow exited the automated milking system $(\sim 1$ h). Additionally, feed bins were closed for 30 min before F1 (from 1330 to $1359 \mathrm{~h}$ ) each day, while the previous days' refusals were sampled and the bins were cleaned out. The total amount of feed offered was adjusted to target approximately $10 \%$ daily refusals per cow.

\section{Behavioral Data Collection}

Data collected from the Insentec system provided the time each feeding visit occurred, the visit duration, and the amount of feed consumed per visit. For each recording period, these data were used to calculate daily DMI $(\mathrm{kg} / \mathrm{d})$, daily feeding time $(\mathrm{min} / \mathrm{d})$, and average feeding rate $(\mathrm{kg}$ of $\mathrm{DM} / \mathrm{min}$ ) for each cow. The DMI, feeding 
time, and feeding rate were also analyzed across treatments for the first hour after each feed delivery and milking time, because this has been identified as the period of peak feed bunk attendance and DMI (DeVries et al., 2003a; DeVries and von Keyserlingk, 2005; King et al., 2016).

Meals were determined by combining individual feeding visits according to the methods described by DeVries et al. (2003b). Meal criteria (defined as the minimum time interval between meals) were determined for each cow during each recording period using Mix 3.1.3 software (MacDonald and Green, 1988) by fitting normal distributions to the frequency of $\log _{10^{-}}$ transformed intervals of time between feeding visits, as collected from the Insentec system. Meal frequency (no./d) was determined by summarizing the number of intervals between feeding visits that exceeded the individual meal criterion of each cow. Meal length (min/ meal) was calculated as the time between the start of the first feeding visit and the end of the last feeding visit before the meal criterion was surpassed. Meal size ( $\mathrm{kg}$ of $\mathrm{DM} /$ meal) was calculated as DMI divided by meal frequency.

Replacements were defined, as per Huzzey et al. (2014), as instances when the actor (initiator) of an aggressive interaction at a feed bin was the next to occupy the same feed bin, once the reactor (feeding cow) had exited. The daily number of times a cow was involved in a replacement from the feed bin was determined using electronically recorded feeding behavior from the Insentec system, according to the methods validated by Huzzey et al. (2014). Consistent with these methods, the frequency of replacements was identified as when $\leq 26$ s had elapsed between the exit of 1 cow from a feed bin and the entrance of another. The number of times each cow was involved as either the actor or reactor in a replacement were summarized, and a replacement success index (SI) was determined as a measure of individual success in competitive interactions. The SI was calculated as the number of times each cow was the actor of a replacement, divided by the number of times the cow was the actor or the reactor (Galindo and Broom, 2000; Val-Laillet et al., 2008). Using this SI, each cow was categorized as having low, medium, or high competitive success, according to the methods described by Huzzey et al. (2012a); cows with an SI $<0.4$ were ranked as low, those with an SI $\geq 0.4$ to $<0.6$ were ranked as medium, and those with an SI $\geq 0.6$ were ranked as high.

Standing and lying behavioral data were recorded using data loggers (Hobo Pendant G Logger; Onset Computer Corporation, Pocasset, MA), as validated by Ledgerwood et al. (2010). Data loggers were affixed to the rear hock of each cow using veterinary bandaging tape (Vetrap Bandaging Tape; 3M, London, ON, Canada) before the start of d 6 and removed after the end of d 10 in each recording period. Leg orientation data were recorded at 1-min intervals and used to compute standing and lying duration $(\mathrm{min} / \mathrm{d})$, lying bout frequency (bouts/d), and lying bout length (min/bout).

Rumination behavior was recorded electronically using automatic rumination detection loggers (Lely Qwes-HR collars; Lely Industries N.V., Maassluis, the Netherlands), as validated by Schirmann et al. (2009). Loggers were attached to a collar and lay on the left side of each cow's neck, where they recorded sounds of regurgitation and rumination with a microphone. These data were processed, summarized in 2-h intervals, and stored in the memory of the logger for up to $22 \mathrm{~h}$ before being automatically uploaded via a reader inside the automated milking system unit. The resulting rumination-time data were downloaded after the completion of each recording period and then summarized for each cow, by day and by 2 -h interval per day.

\section{Feed Sampling and Analyses}

Feed samples were collected during each recording period; on d 6 and 7, 1 composite sample of fresh offered feed from the bins of each subgroup was taken at each feeding to determine DM. On d 8 to 10, a composite sample of each of the offered and refused feed was taken from the bins of each subgroup, at each feeding, to determine DM and differences in sorting. At F2 and F3, new feed was added to each bin and mixed thoroughly with any remaining orts before sampling the offered feed. Samples of TMR components were collected once weekly to be analyzed for DM, chemical composition, and particle size. All feed samples were frozen at $-14^{\circ} \mathrm{C}$ upon collection until further analysis.

Each sample for sorting determination was separated using a 3-screen Penn State Particle Separator (Kononoff et al., 2003) into long $(>19 \mathrm{~mm})$, medium $(<19$, $>8 \mathrm{~mm})$, short $(<8,>1.18 \mathrm{~mm})$, and fine $(<1.18 \mathrm{~mm})$ particles. The subsequent fractions, in addition to the whole samples used for DM determination, were ovendried at $55^{\circ} \mathrm{C}$ for $48 \mathrm{~h}$. All dried samples of TMR feed components and fresh TMR (whole samples and Penn State Particle Separator fractions) were ground (Wiley Mill; Arthur H. Thomas Co., Philadelphia, PA) and passed through a $1 \mathrm{~mm}$ screen; ground samples were shipped to Cumberland Valley Analytical Services Inc. (Maugansville, MD) for analysis of DM $\left(135^{\circ} \mathrm{C}\right.$; AOAC International, 2000; method 930.15$)$, ash $\left(535^{\circ} \mathrm{C}\right.$; AOAC International, 2000; method 942.05), ADF (AOAC, 2000; method 973.18), and NDF with heat-stable 
Q-amylase and sodium sulfite (Van Soest et al., 1991). The chemical composition of the TMR is described in Table 1; particle size distribution and nutrient content by particle size fraction are described in Table 2 .

Feed sorting was determined by dividing the DM amount of each particle fraction actually consumed by the predicted DM amount consumed for the same fraction, and expressing it as a percentage (Leonardi and Armentano, 2003). The results of the Penn State Particle Separator analysis were used to determine the actual and predicted DM consumed by each subgroup. The actual DM consumed was calculated as the DM proportion of each particle fraction of refused feed subtracted from the DM proportion of each particle fraction in the offered feed. The predicted DM consumed was calculated as the proportion of total DMI for each particle fraction. Resulting values equal to $100 \%$ indicated no sorting of the fraction, values $>100 \%$ indicated sorting in favor of that fraction (actual consumption was greater than predicted), and values $<100 \%$ indicated sorting against that fraction (actual consumption was less than predicted). The greater the deviation from $100 \%$, the greater the amount of sorting, either for or against a particular particle size fraction.

\section{Milk Production and Components}

Milk yield data were collected daily by the automated milking system and extracted for d 6 to 10 in each recording period; milk quality was recorded on d 8 and 10. The Lely AMS Shuttle Sampling Device (Lely Industries N.V., Maassluis, the Netherlands) was used to sample milk from each cow at each milking on

Table 2. Particle size distribution ${ }^{1}$ (mean $\pm \mathrm{SD}$ ) and nutrient content (mean $\pm \mathrm{SD}$ ) by particle size of the fresh experimental diet

\begin{tabular}{lr}
\hline Item & Diet \\
\hline \% of DM retained on screen & \\
Long & $5.5 \pm 1.76$ \\
Medium & $40.3 \pm 3.33$ \\
Short & $38.3 \pm 2.73$ \\
Fine & $15.9 \pm 1.72$ \\
NDF (\% of screen DM) & \\
Long & $56.1 \pm 1.36$ \\
Medium & $36.7 \pm 1.15$ \\
Short & $32.2 \pm 1.50$ \\
Fine & $22.2 \pm 1.10$ \\
CP (\% of screen DM) & \\
Long & $11.7 \pm 1.33$ \\
Medium & $15.9 \pm 0.50$ \\
Short & $19.3 \pm 1.08$ \\
Fine & $24.0 \pm 1.21$ \\
\hline
\end{tabular}

${ }^{1}$ Particle size was determined using the Penn State Particle Separator, which has a 19-mm screen (long), an 8-mm screen (medium), a 1.18$\mathrm{mm}$ screen (short), and a pan (fine). those days. All milk samples on d 8 and 10, separate for each milking, were sent to a DHI testing laboratory (CanWest DHI, Guelph, ON, Canada) for component analysis (fat, protein, and MUN) by a Fourier transform infrared spectrometer, full spectrum analyzer (Milkoscan FT+ and Milkoscan 6000; Foss, Hillerød, Denmark). These data were averaged across milkings to create 1 value per cow per sampling day.

For each day that milk samples were collected, $4 \%$ FCM $(\mathrm{kg} / \mathrm{d})$ was calculated as $0.4 \times$ milk yield $(\mathrm{kg} / \mathrm{d})$ $+15.0 \times$ fat yield $(\mathrm{kg} / \mathrm{d})(\mathrm{NRC}, 2001)$, and ECM yield $(\mathrm{kg} / \mathrm{d})$ was calculated as $(0.327 \times \mathrm{kg}$ of milk $)+(12.95$ $\times \mathrm{kg}$ of fat $)+(7.2 \times \mathrm{kg}$ of protein) (Tyrrell and Reid, 1965). The efficiency of milk production was calculated as kilograms of milk, 4\% FCM yield, and ECM yield per $\mathrm{kg}$ of DMI per cow.

\section{Statistical Analyses}

All analyses were performed using SAS software (version 9.4; SAS Institute Inc., 2013), with significance declared at $P \leq 0.05$, and tendencies reported if 0.05 $<P \leq 0.10$. Interactions were considered only if they met the level of $P \leq 0.05$. Data were tested for normality before analysis using the UNIVARIATE procedure, and the assumptions of normality were met for all variables. Data from each variable were summarized by subgroup and period (the 5 recording days of each treatment period); subgroups were considered experimental units, because the treatments were applied at that level. These data were then analyzed in a general linear mixed model. The MIXED procedure was used, with the fixed effects of treatment, period, and treatment $\times$ period interaction; the random effects were group and subgroup within group. Degrees of freedom were estimated using the Kenward-Rogers adjustment in the MODEL statement. To find the best fit to the data, contrast statements were included to fit both the linear and quadratic response to treatments; all values reported are least squares means. Additionally, to test our hypothesis that competition for feed access would increase within-group variability, the daily standard deviation of each subgroup was calculated for each measure and averaged across each period. The resulting data were analyzed using the above-mentioned model.

Because rank of competitive success was determined at the individual cow level, the effect of rank on feeding time, feeding rate, and DMI by treatment was summarized by cow and treatment. They were then tested using the MIXED model described previously, including the additional fixed effects of rank and the interaction of rank and treatment. The effects of individual cow BW and parity were also considered for this model. 
Body weight and parity were correlated, thus only BW was included; BW was removed from the model and not reported further when it was found to be not significant.

To test for feed sorting on each treatment, sorting activity was summarized by subgroup and period for each particle fraction at each feeding and tested for a difference from $100 \%$ using a $t$-test. Differences in sorting by treatment and feeding were compared using a repeatedmeasures mixed model, treating feeding as a repeated measure. The fixed effects were treatment, feeding (F1, F2, and F3), period, and the interactions of treatment $x$ feeding and treatment $x$ period. The random effect was group, and the subject of the repeated statement was subgroup within group. The variance-covariance matrix structure used was compound symmetry, chosen on the basis of best fit according to Schwarz's Bayesian information criterion. Contrast statements were used to determine linear or quadratic response to treatment effects. The Kenward-Roger adjustment for degrees of freedom was included in the MODEL statement, and all values were reported as least squares means. If interactions of treatment $\times$ feeding were detected, the data were then analyzed by feeding (F1, F2, and F3), using the first-described model to determine the effect of treatment.

\section{RESULTS}

Feeding time decreased in a quadratic manner as the level of feeding competition increased (Table 3), with the least time spent feeding under high competition. Because we found no difference in DMI between treatments, we observed a similar quadratic response in feeding rate as competition level increased, with the lowest rate of feed consumption under low competition.

In the hour immediately following each fresh feed delivery and milking, feeding time (Figure 1a) showed a quadratic response to increasing competition after the first 2 feedings $\left(\mathrm{F} 1: \mathrm{SE}=2.15, P_{\text {quadratic }}=0.005 ; \mathrm{F} 2\right.$ : $\left.\mathrm{SE}=1.85, P_{\text {quadratic }}=0.01\right)$, but we observed no significant difference following $\mathrm{F} 3(\mathrm{SE}=2.29, P \geq 0.11)$. After the first 2 feed deliveries of the day, feeding time was lower under the high competition treatment than under the low and moderate treatments. For the same peak periods, feeding rate (Figure 1b) demonstrated an opposite quadratic effect to increased competition, with high competition eliciting the highest rate of feed consumption following F1 $\left(\mathrm{SE}=0.04, P_{\text {quadratic }}=0.03\right)$ and F2 $\left(\mathrm{SE}=0.02, P_{\text {quadratic }}=0.03\right)$, and demonstrating a tendency for a higher rate following $\mathrm{F} 3(\mathrm{SE}=0.02$, $\left.P_{\text {quadratic }}=0.07\right)$. Similar to the daily summarized data, the opposing responses of feeding time and feeding rate resulted in no detected effect of competition level on DMI in the hour after each feed delivery and milking (Figure 1c).

We found quadratic associations between competition for feed access and meal patterns (Table 3). Meal criteria, meal length, and non-feeding time within meals results were similar at low and moderate competition, and they were greater at high competition. This was particularly evident for the non-feeding time, which under high competition was approximately twice as long as that for both low and moderate competition. We also observed a tendency for a quadratic effect on meal frequency and meal size, observing fewer and

Table 3. Effect of 3 competition levels on feeding behavior, rumination time, and lying behavior in groups of lactating Holstein dairy cows ${ }^{1}$

\begin{tabular}{|c|c|c|c|c|c|c|}
\hline \multirow[b]{2}{*}{ Item } & \multicolumn{3}{|c|}{ Treatment $^{2}$} & \multirow[b]{2}{*}{ SEM } & \multirow[b]{2}{*}{$P_{\text {linear }}^{3}$} & \multirow[b]{2}{*}{$P_{\text {quadratic }}$} \\
\hline & Low & Moderate & High & & & \\
\hline Feeding time $(\min / \mathrm{d})$ & 202.6 & 194.9 & 183.6 & 8.84 & 0.006 & 0.008 \\
\hline Feeding rate ( $\mathrm{kg}$ of $\mathrm{DM} / \mathrm{min})$ & 0.16 & 0.18 & 0.20 & 0.01 & 0.003 & 0.007 \\
\hline DMI $(\mathrm{kg} / \mathrm{d})$ & 29.3 & 29.0 & 29.1 & 0.67 & 0.51 & 0.82 \\
\hline Meal criterion (min) & 38.3 & 36.2 & 58.6 & 5.88 & 0.005 & 0.002 \\
\hline Meal frequency (no./d) & 7.9 & 8.0 & 7.5 & 0.58 & 0.12 & 0.06 \\
\hline Interval between meals (min) & 160.1 & 159.4 & 171.4 & 16.32 & 0.18 & 0.12 \\
\hline Meal size $(\mathrm{kg}$ of $\mathrm{DM} / \mathrm{meal})$ & 3.9 & 3.9 & 4.3 & 0.48 & 0.12 & 0.06 \\
\hline Meal length $(\mathrm{min} / \mathrm{meal})$ & 37.0 & 36.6 & 47.3 & 5.05 & 0.03 & 0.02 \\
\hline Non-feeding time within meals (min/meal) & 10.0 & 10.8 & 20.3 & 3.24 & 0.004 & 0.003 \\
\hline Replacement frequency (no./d) & 2.7 & 3.6 & 4.1 & 0.64 & 0.15 & 0.25 \\
\hline Rumination $(\min / \mathrm{d})$ & 514.1 & 513.9 & 511.6 & 8.27 & 0.74 & 0.71 \\
\hline Lying time $(\mathrm{h} / \mathrm{d})$ & 10.2 & 10.2 & 9.5 & 0.51 & 0.09 & 0.05 \\
\hline Lying bout frequency (no./d) & 10.5 & 10.9 & 10.3 & 1.01 & 0.78 & 0.47 \\
\hline Bout length (min/bout) & 63.7 & 62.5 & 61.8 & 6.35 & 0.60 & 0.68 \\
\hline
\end{tabular}

${ }^{1}$ Data were averaged over 5 d for 6 subgroups (each containing 3 cows) on each treatment.

${ }^{2}$ Competition-level treatments: low $=3$ cows: 3 feed bins; moderate $=3$ cows: 2 feed bins; and high $=3$ cows: 1 feed bin.

${ }^{3} P_{\text {linear }}=$ linear response to treatment.

${ }^{4} P_{\text {quadratic }}=$ curvilinear response to treatment. 

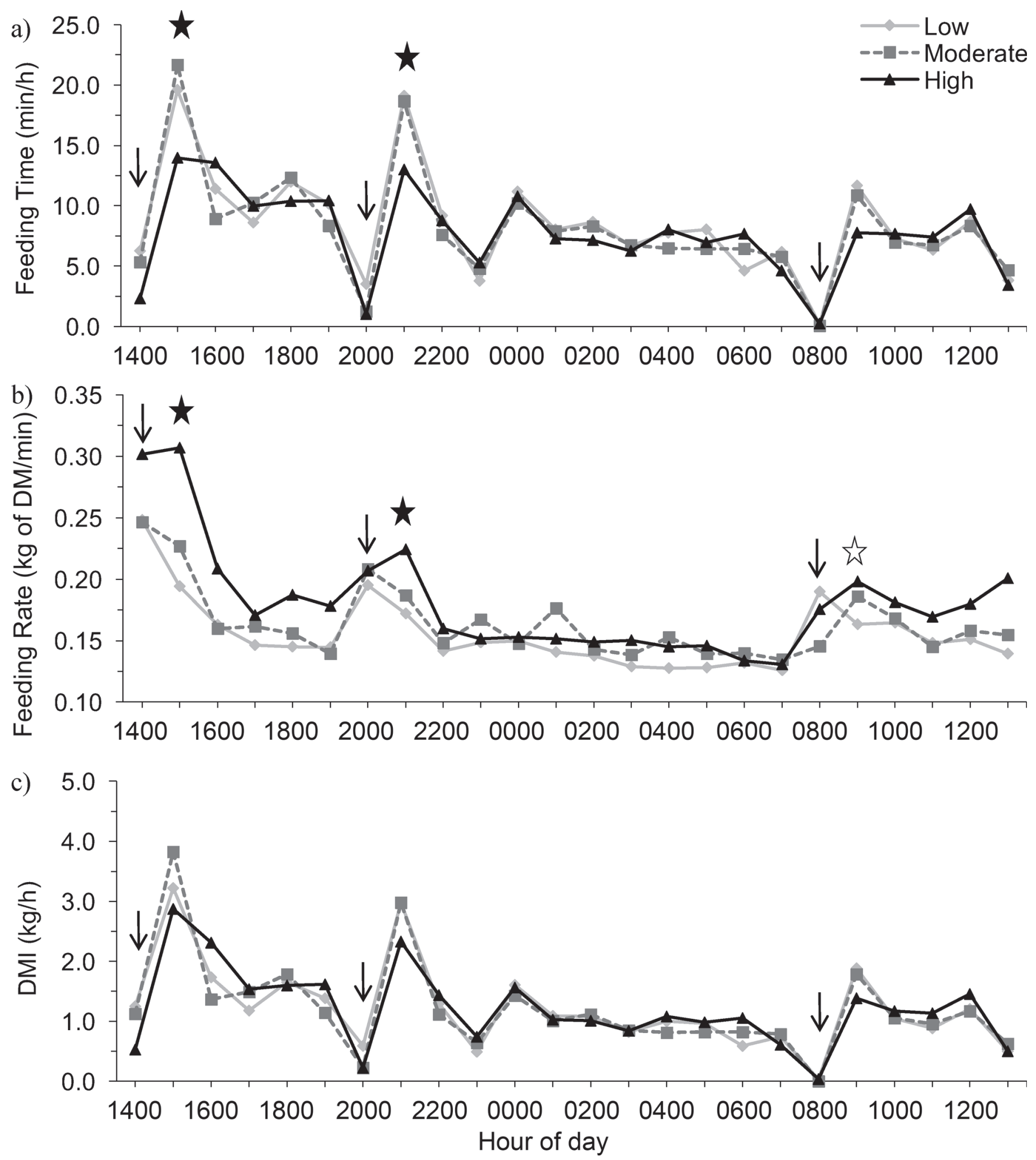

Figure 1. Average (a) feeding time ( $\mathrm{min} / \mathrm{h} ; \mathrm{SE}=1.35)$; (b) feeding rate $(\mathrm{kg}$ of $\mathrm{DM} / \mathrm{min} ; \mathrm{SE}=0.02)$, and $(\mathrm{c}) \mathrm{DMI}(\mathrm{kg} / \mathrm{h} ; \mathrm{SE}=0.21)$ by hour of the day for lactating Holstein dairy cows fed under low (3 cows:3 feed bins), moderate (3 cows:2 feed bins), and high (3 cows: 1 feed bin) competition treatments. Cows were milked and delivered feed $3 \times / \mathrm{d}$ at 1400, 2000, and $0800 \mathrm{~h}$ (denoted by $\downarrow$ ). Recording began at the first fresh feeding after daily emptying of the feed bins. Data were averaged over 5 d for 6 subgroups (each containing 3 cows) on each treatment. Filled stars indicate hours demonstrating differences $(P \leq 0.05)$ between treatments, and open stars indicate tendencies for differences $(0.05<P \leq 0.10)$. 
Table 4. Effect of 3 competition levels on sorting $(\%)^{1}$ of long, medium, short, and fine particle sizes at each feeding of the day in groups of lactating Holstein dairy cows ${ }^{2}$

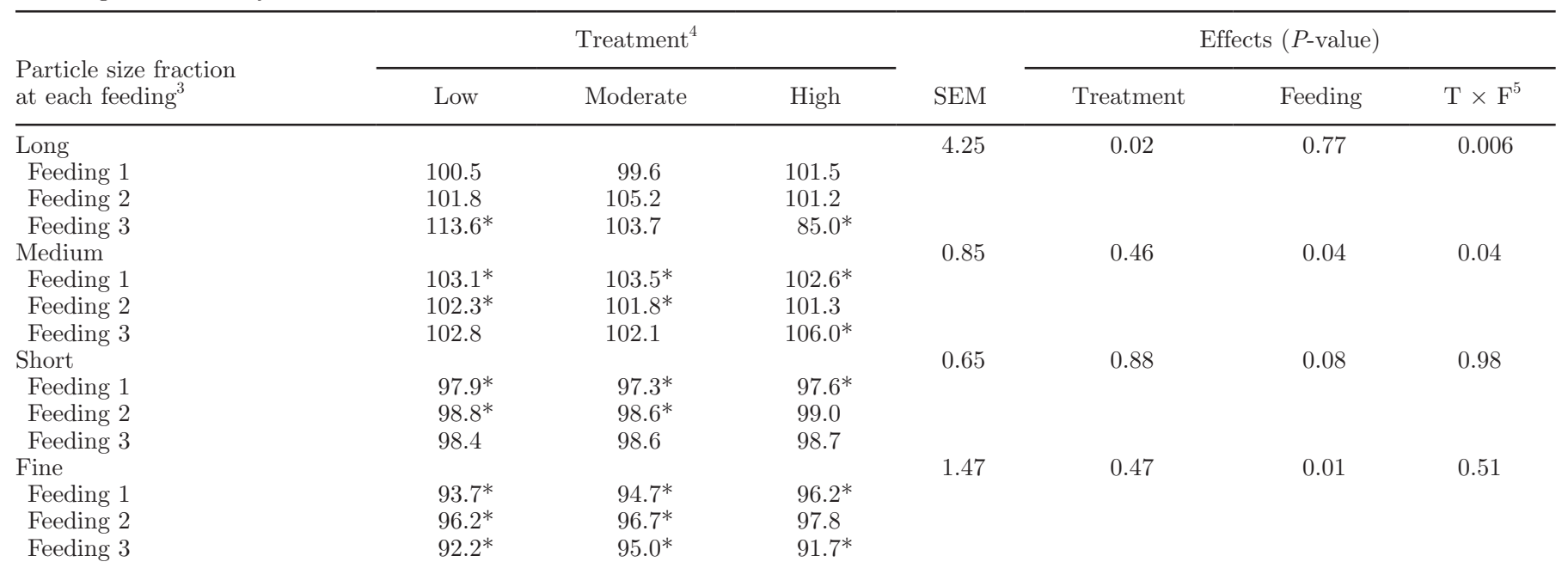

${ }^{1}$ Sorting $\%$ for each fraction $=($ actual DMI/predicted DMI $) \times 100$. Sorting values: $100 \%$ indicates no sorting, $<100 \%$ indicates selective refusals (sorting against), and $>100 \%$ indicates preferential consumption (sorting for).

${ }^{2}$ Data were averaged over 5 d for 6 subgroups (each containing 3 cows) on each treatment.

${ }^{3}$ A 3-screen Penn State Particle Separator was used to separate samples into 4 particle size fractions: long $(>19 \mathrm{~mm})$, medium $(<19 \mathrm{~mm},>8$ $\mathrm{mm})$, short $(<8 \mathrm{~mm},>1.8 \mathrm{~mm})$, and fine $(<1.8 \mathrm{~mm})$. Cows were fed $3 \times / \mathrm{d}$ at $1400 \mathrm{~h}$ (feeding 1$), 2000 \mathrm{~h}($ feeding 2$)$, and $0800 \mathrm{~h}($ feeding 3 ).

${ }^{4}$ Competition-level treatments: low $=3$ cows: 3 feed bins; moderate $=3$ cows: 2 feed bins; and high $=3$ cows: 1 feed bin.

${ }^{5} \mathrm{~T} \times \mathrm{F}=$ interaction of treatment and feeding.

*Indicates sorting was different from $100 \%(P \leq 0.05)$.

larger meals under high competition than under low and moderate competition. We detected no effect of treatment on the time interval between meals.

We detected no effect of increased levels of competition on the daily frequency of replacements (Table 3 ); however, analysis of the hour following each feed delivery revealed a tendency for reduced replacements under low competition after F1 (low $=0.7$, moderate $=1.5$, high $=1.4$ replacements $/ 1 \mathrm{~h}$ post-feeding; $\mathrm{SE}=$ $\left.0.24 ; P_{\text {linear }}=0.07\right)$. We detected no effect of treatment on the frequency of replacements following F2 and F3 $(P \geq 0.62)$. The analysis of intake by rank indicated an effect on feeding time $(P=0.03)$, where high-ranking cows had greater feeding times than cows with low or medium ranks of competitive success (data not shown). Neither feeding rate nor DMI was associated with rank.

Competition level had a quadratic effect on lying time, with a mean reduction of $42 \mathrm{~min} / \mathrm{d}(0.7 \mathrm{~h} / \mathrm{d})$ under high competition compared with low and moderate (Table 3). We detected no effect of treatment on the frequency of lying bouts or lying bout length, nor did we detect an effect of competition level on daily rumination time.

We observed a treatment $\times$ feeding interaction for sorting of both long $(>19 \mathrm{~mm})$ and medium particles $(>8,<19 \mathrm{~mm}$; Table 4$)$. The interaction revealed that sorting of long particles varied in a quadratic manner
$\left(P_{\text {quadratic }}=0.02\right)$ by treatment at F3: under low competition, cows sorted in favor of long particles, but under high competition, they sorted against long particles (Table 4). We also observed a tendency for a quadratic effect $\left(P_{\text {quadratic }}=0.09\right)$ of competition on the sorting of medium particles at F3: cows sorted in favor of medium particles under high competition but did not sort for or against these particles in the other treatments (Table 4). We detected no differences in the sorting of short and fine particles between treatments, but cows primarily sorted against these particles across all treatments and feedings. The extent of sorting varied by feeding, with the greatest sorting against short and fine particles occurring after F1 and F3, respectively.

Competition level did not influence total milk yield, but we observed a tendency for a quadratic effect on $4 \%$ FCM and ECM; these were lowest at high competition (Table 5). We also found a quadratic response on milk protein yield, which was lower under high competition than under low and moderate. We observed a quadratic increase in MUN with greater competition, but no effects of competition level on milk composition or efficiency of production.

Analyses revealed a linear increase in within-group variation in feeding time, as well as a quadratic increase in variation in feeding rate with higher competition (Table 6). We detected no effect of competition on 
Table 5. Effect of 3 competition levels on milk production and composition in groups of lactating Holstein dairy cows ${ }^{1}$

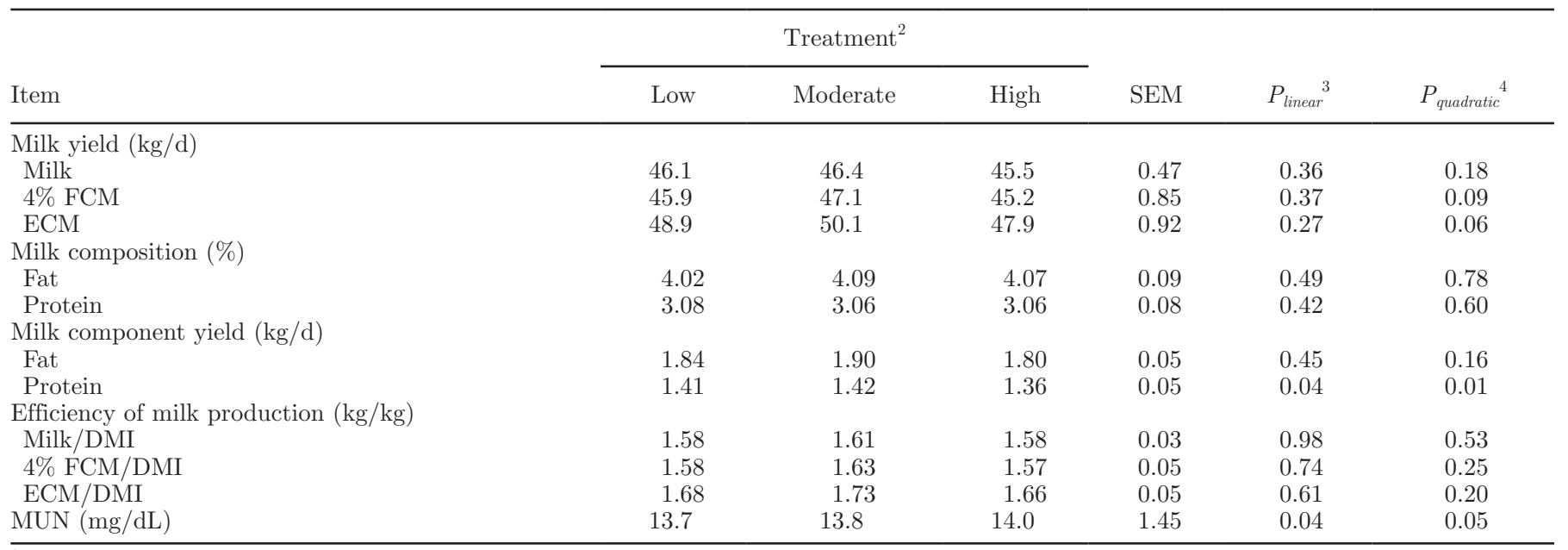

${ }^{1}$ Data were averaged over $5 \mathrm{~d}$ (yield) or $2 \mathrm{~d}$ (composition and efficiency), for 6 subgroups (each containing 3 cows) on each treatment.

${ }^{2}$ Competition-level treatments: low $=3$ cows: 3 feed bins, moderate $=3$ cows: 2 feed bins; and high $=3$ cows: 1 feed bin.

${ }^{3} P_{\text {linear }}=$ linear response to treatment.

${ }^{4} P_{\text {quadratic }}=$ curvilinear response to treatment.

within-group variability in DMI. Because of quadratic effects, the variability observed in meal patterns was much greater under high competition than under low or moderate for meal criteria, meal length, and nonfeeding time within meals. We detected no effect of increased competition on within-group variability in meal frequency, meal size, and the interval between meals. We observed a tendency for a quadratic effect on variability in lying time, with cows under high competition demonstrating greater within-group variability than cows under low and moderate. We found no effect of competition level on within-group variability in lying bout frequency, bout length, daily rumination time, or frequency of daily replacements.

Milk data analyses (Table 7) indicated that a linear increase in the within-group variability in milk yield, $4 \%$ FCM, and ECM with increased competition for feed access. We observed a quadratic effect on variability in milk fat percentage and the milk protein component yield $(\mathrm{kg} / \mathrm{d})$, both demonstrating reduced variability at low competition compared with moderate and high. We also observed a tendency for a linear increase in

Table 6. Effect of 3 competition levels on within-group variability ${ }^{1}$ in feeding behavior, rumination time, and lying behavior in groups of lactating Holstein dairy cows

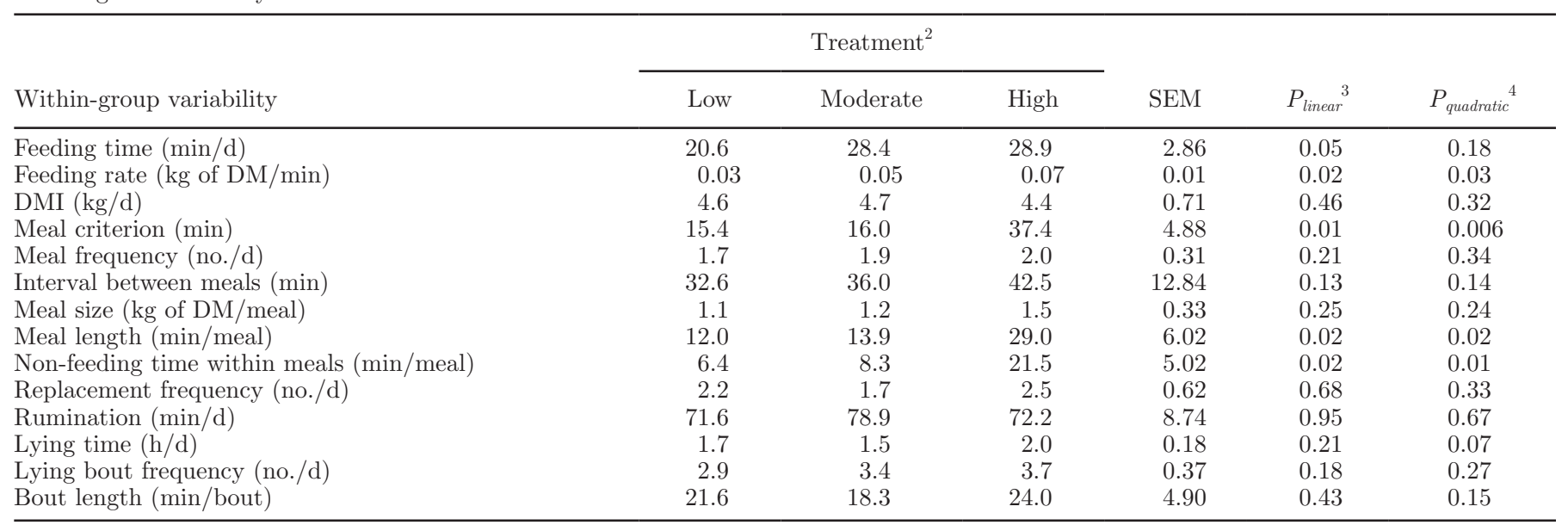

${ }^{1}$ Calculated as the daily standard deviation of each group averaged over $5 \mathrm{~d}$ for 6 subgroups (each containing 3 cows) on each treatment.

${ }^{2}$ Competition-level treatments: low $=3$ cows: 3 feed bins; moderate $=3$ cows: 2 feed bins; and high $=3$ cows: 1 feed bin.

${ }^{3} P_{\text {linear }}=$ linear response to treatment.

${ }^{4} P_{\text {quadratic }}=$ curvilinear response to treatment. 
the variability in milk fat component yield $(\mathrm{kg} / \mathrm{d})$ as competition level increased. We observed a tendency for a quadratic effect of competition for feed access on variability in efficiency of milk production $(\mathrm{kg}$ milk $/ \mathrm{kg}$ DMI), which was greatest under high competition.

\section{DISCUSSION}

The elevated levels of feeding competition tested in this study represent both average and extreme conditions and, as such, did not follow a linear pattern. The low and moderate competition treatments corresponded to 100 and $150 \%$ stocking densities at the feed bunk, respectively, and high represented a 300\% stocking density. These levels of competition make linear relationships between competition and feeding behavior unlikely, so we expected to find primarily quadratic relationships for the majority of the variables investigated in this study.

In support of our hypothesis, at the highest level of competition cows spent the least time feeding, but at the highest rate of consumption. This behavioral pattern was demonstrated on a daily basis and during the periods of peak feeding activity following the first 2 feed deliveries (F1 and F2). Researchers have found that increasing competition through greater stocking density of feed bunks leads to reduced daily feeding times (DeVries et al., 2004; Huzzey et al., 2006). Across treatments, cows that were more successful in gaining access to the feed bin (i.e., cows that had a higher rank of competitive success) were able to spend a lon- ger time feeding. These corresponded with the most dominant animals in the group, because more dominant cows have been shown to spend a significantly longer proportion of time at the feed bunk than subordinate cows (Grant and Albright, 2001; Val-Laillet et al., 2008). Olofsson (1999) compared the effects of competition at levels of 1 or 4 cows per feeding station and found decreased feeding times and increased feeding rates under higher competition; this effect was more pronounced in subordinate cows, which tended to alter their feeding behavior to a greater extent than dominant cows. Increasing feeding rate allows individuals to indirectly compete for feed (Giraldeau and Caraco, 2000), which may be beneficial for lower-ranked cows that cannot compete by displacing others from the feed bunk. Such a discrepancy between dominant and subordinate cows is likely to be the cause of the greater within-group variability we observed in both feeding time and rate of feed intake as competition increased. This finding supported our hypothesis that individuals in the group would experience greater variability in feed-consumption patterns, and suggests that with greater social pressure at the feed bunk, some cows can better manage the effects of competition than others.

The ability of dairy cows to modify their feed intake patterns by eating faster and over shorter periods allows them to compensate for increased social pressure at the feed bunk. We observed this in the present study: both daily and peak period DMI remained constant across all competition levels. Similarly, Hosseinkhani et al. (2008) found increased feeding rates, but no effect

Table 7. Effect of 3 competition levels on within-group variability ${ }^{1}$ in milk production and composition in groups of lactating Holstein dairy cows

\begin{tabular}{|c|c|c|c|c|c|c|}
\hline Within-group variability & \multicolumn{3}{|c|}{ Treatment $^{2}$} & SEM & $P_{\text {linear }}^{3}$ & $P_{\text {quadratic }} 4$ \\
\hline $4 \% \mathrm{FCM}$ & 6.5 & 7.9 & 7.8 & 1.51 & 0.04 & 0.19 \\
\hline ECM & 6.7 & 8.2 & 8.2 & 1.56 & 0.02 & 0.12 \\
\hline \multicolumn{7}{|l|}{ Milk composition (\%) } \\
\hline \multicolumn{7}{|c|}{ Milk component yield (kg/d) } \\
\hline Fat & 0.28 & 0.35 & 0.36 & 0.10 & 0.06 & 0.17 \\
\hline Protein & 0.17 & 0.22 & 0.22 & 0.04 & 0.004 & 0.05 \\
\hline \multicolumn{7}{|c|}{ Efficiency of milk production $(\mathrm{kg} / \mathrm{kg})$} \\
\hline Milk/DMI & 0.18 & 0.16 & 0.21 & 0.02 & 0.20 & 0.08 \\
\hline $4 \%$ FCM/DMI & 0.14 & 0.15 & 0.17 & 0.02 & 0.31 & 0.27 \\
\hline ECM/DMI & 0.15 & 0.15 & 0.18 & 0.02 & 0.33 & 0.28 \\
\hline
\end{tabular}

${ }^{1}$ Calculated as the daily standard deviation of each group averaged over $5 \mathrm{~d}$ (yield) or $2 \mathrm{~d}$ (composition and efficiency), for 6 subgroups (each containing 3 cows) on each treatment.

${ }^{2}$ Competition-level treatments: low $=3$ cows: 3 feed bins; moderate $=3$ cows: 2 feed bins; and high $=3$ cows: 1 feed bin.

${ }^{3} P_{\text {linear }}=$ linear response to treatment.

${ }^{4} P_{\text {quadratic }}=$ curvilinear response to treatment. 
of competition on daily DMI. In their study, DMI was lower for competitively fed cows in the hours surrounding feedings, but higher through the remainder of the day, allowing equivalent net DMI for both competitively and non-competitively fed cows. It should be noted that increasing feed consumption rate to maintain DMI might negatively affect rumen health. Rapid ingestion of larger meals results in declining rumen $\mathrm{pH}$ (Allen, 1997), and salivation rate is higher when feed is consumed more slowly (Maekawa et al., 2002; Beauchemin et al., 2008). Using estimates of salivation rate from Maekawa et al. (2002) for cows fed a ration of similar forage content, the increased feeding rate we observed $(20 \mathrm{~g} \mathrm{DM} / \mathrm{min})$ would result in approximately $16.4 \mathrm{~L} / \mathrm{d}$ less saliva as the competition level increased from low to moderate, and an equivalent reduction from moderate to high. This is in comparison to an estimated 44-56 L/d of total saliva production (Maekawa et al., 2002). Because saliva is an important factor in maintaining the buffering capacity of the rumen, and in limiting the magnitude of $\mathrm{pH}$ decline while feeding (Allen, 1997; Beauchemin, 2007), such a reduction in saliva production could increase the cow's risk of developing ruminal acidosis. Rumination activity is also known to affect saliva production (Beauchemin, 2007), but we observed no apparent effect of increased competition for feed access on daily or within-group variability in rumination time.

Despite the faster feeding rate and shorter feeding times we observed, meal criteria and meal length were longest under high competition. We attributed this to the greatly elevated non-feeding time within meals, indicating that cows were waiting to gain access to occupied feed bins. Similarly, Proudfoot et al. (2009) found that increased meal length was due to greater non-feeding time within meals among primiparous transition cows. They observed that non-feeding time within meals increased by $46 \%$ between the non-competitive (1:1) and competitive (2:1) treatment levels; however, this finding corresponds most closely our low (1:1) and moderate (1.5:1) competition treatment levels, where we found an increase of only $8 \%$. The smaller change in non-feeding time that we observed was likely driven by the greater nutrient intakes of cows closer to peak lactation compared with transition cows, enhancing their motivation to compete for feed access and resulting in less time spent waiting within meals. When we compared the low (1:1) to high (3:1) competition levels in our study, non-feeding time within meals increased by $103 \%$. This suggests that lactating cows were able to compensate for a moderate level of competition by altering their feeding behavior, but as that competition increased, the cows became less able to compete and were forced to increase their idle stand- ing time. This finding supports previous research that demonstrated greater idle standing time in the feed area with increased stocking density at the feed bunk (Huzzey et al., 2006). Prolonged time standing on hard surfaces has been associated with an increased risk of lameness due to claw horn lesions (Greenough and Vermunt, 1991; Cook et al., 2004) and could be especially problematic for subordinate cows that experience the greatest increases in daily standing times, particularly surrounding peak feeding periods (Galindo and Broom, 2000; DeVries and von Keyserlingk, 2006).

With changes to feeding time and length of meals, there should be a corresponding effect on the time allotted to other behaviors in the cows' daily time budget. The tendency for reduced meal frequency accounts for some of this time, and together with the tendency for increased meal size under high competition, is similar to a study by Hosseinkhani et al. (2008) which found fewer, longer, and larger meals in competitively fed transition cows. Management practices that promote such intake patterns may put cows at increased risk of subacute ruminal acidosis and laminitis (Shaver, 2002; Krause and Oetzel, 2006). Additionally, in the current study, cows' time budget was affected by a 42 -min reduction in daily lying time under high competition. Within-group variation in lying time also demonstrated a slight curvilinear increase, indicating a tendency toward more variation in lying time under high competition. When resources are restricted, lying time is a high-priority behavior that takes precedence over feeding and social contact (Munksgaard et al., 2005); however, even though cows were able to compensate for increased competition via a higher feeding rate and reduced feeding time, the time spent waiting to access feed under high competition remained sufficient to require a reduction in lying time, despite its importance to the daily time budget.

In support of our second hypothesis, we observed greater within-group variability in meal patterns: meal criteria, meal length, and non-feeding time within meals all demonstrated more variability under high competition than at the lower levels, reflecting the same curvilinear response as at the group level. Proudfoot et al. (2009) found that parity played a role in the differences in meal patterns under competition. They observed that primiparous transition cows fed competitively tended to have longer meals in the first week after calving than those fed without competition, but multiparous cows showed no differences in meal length for the same periods. Further research into the effect of parity under increased levels of competition could help to explain the differing ability of individual cows to cope with increased competitive pressure at the feed bunk. 
Surprisingly, cows primarily sorted the TMR neither for nor against long particles, instead sorting in favor of medium particles and against short and fine particles. These findings were contrary to previously reported data indicating that cows typically sort against larger particles and in favor of smaller particles (Leonardi and Armentano, 2003; DeVries et al., 2007; Hosseinkhani et al., 2008). The third feeding of the day under high competition was the only feeding in which sorting against long particles occurred; cows compensated for this selective refusal by increasing their consumption of medium particles. The results of the present study, however, are not unprecedented; DeVries et al. (2008) also found that cows sorted for medium particles and against long, short, and fine particles. They attributed this anomalous finding to cows selecting for the grain supplement pellet in the medium particle fraction, and to the settling or loss of fine particles to the floor as cows pushed and sort the TMR in the bunk. In the present study, medium particles were the most abundant component of the experimental diet (Table 2), and this could explain the increased selection for that fraction. A study of feed sorting in tie-stall cows by Miller-Cushon and DeVries (2010) also found increased sorting in favor of medium particles and against short particles when feeding a comparable ration composed of $>50 \%$ medium particles on a DM basis. The authors suggested that the greater availability of highly palatable, high-moisture corn in the medium fraction might have motivated this selective consumption.

Competition level had only a minor effect on the frequency of replacements, which were reduced for the hour after the first feeding under low competition, yet we observed no effect on the frequency of daily replacements from the feed bins, contrary to the results of most studies focused on competition for feed access (Olofsson, 1999; Huzzey et al., 2006; Hetti Arachchige et al., 2014). However, displacements were recorded in those studies: a common method uses video recordings to observe when 1 cow forcefully takes the place of another feeding cow. The present study identified replacements according to the methods described by Huzzey et al. (2014), which used the time between sequential feeding visits as recorded by the automated feed bins. Replacements were recorded as instances when a feeding cow was superseded by another within 26 s or less; this method has been validated by Huzzey et al. (2014) and shown to be highly correlated $(\mathrm{r}=0.94)$ with displacements as an indicator of competitive success. The cows used in our study, which were fed in subgroups of 3 individuals at a time, may have been of a sufficiently small group size to easily determine their relative social positions. Because dominance and the establishment of social rank are learned behavior that can persist over long periods (Bielharz and Zeeb, 1982), cows could have made fewer attempts to access the feed bins when a known dominant individual was feeding, reducing the opportunities for replacements to occur. This would be consistent with the findings of Rioja-Lang et al. (2009), that demonstrated subordinate cows chose to eat lowerquality feed alone rather than in proximity to a dominant individual. Furthermore, those researchers found that even when not feeding, subordinate cows spent the majority of their time (83\%) on the unoccupied side of the test arena, rather than in the middle or on the side occupied by the dominant cow. Researchers have suggested that as the number of individuals in a group increases, it becomes more difficult for cows to recognize others and their respective social positions (Grant and Albright, 2001). In larger, more socially complex group sizes, replacements may become more frequent, because the cows would be less able to predict the outcome of a particular interaction.

We noted minor changes to milk production and composition at different levels of competition, including slight decreases in 4\% FCM and ECM, and increases in MUN under high competition; the greatest change was decreased protein yield under high competition. A review of 10 years of milk production studies by Lee et al. (2014) evaluated factors contributing to milk quality and determined that the most influential factor in milk protein and fat yield was DMI. In the present study, we observed no change in daily DMI, but individual fluctuations in intake patterns throughout the day to maintain DMI under varying competition levels could account for the changes in production. We also observed a great deal of within-group variability in milk yield, composition, component yield, and efficiency, indicating that the effect of competition on milk production differed greatly between individuals. Future studies of the long-term effects on milk production may provide a better understanding of the individual effects of restricted feed access as a result of feed bunk competition.

\section{CONCLUSIONS}

Under higher levels of competition for feed access, cows demonstrated increased feeding rates and decreased feeding times that allowed them to maintain daily DMI. The elevated competition also altered meal patterns, resulting in a tendency for cows to consume feed in fewer, larger meals. Those meals were also longer in duration because of greater non-feeding time within meals. As well, we observed greater variability in these feeding patterns among individuals as competition for feed access increased. This research suggests that providing cows with equal opportunities to access feed by 
maintaining lower competition levels promotes healthy feeding behavior patterns, more consistent feed intake, and reduces the variation in time spent eating, the rate of feed consumption, and the productivity between individual cows within a group.

\section{ACKNOWLEDGMENTS}

The authors thank the research and barn staff at the University of Guelph, Kemptville Campus, Dairy Education and Innovation Center (Kemptville, ON, Canada). Special thanks go to Patrick Sudds, Victoria Asselstine, and Kaitlyn Dancy for their help with data collection, and to Albert Koekkoek and Ben Melenhorst for their technical assistance. This project was financially supported by a Natural Sciences and Engineering Research Council of Canada (Ottawa, ON, Canada) Discovery Grant.

\section{REFERENCES}

Allen, M. S. 1997. Relationship between fermentation acid production in the rumen and the requirement for physically effective fiber. J. Dairy Sci. 80:1447-1462. https://doi.org/10.3168/jds.S00220302(97)76074-0.

AOAC International. 2000. Official Methods of Analysis. Vol. I. 17th ed. AOAC International, Arlington, VA.

Beauchemin, K. A. 2007. Ruminal acidosis in dairy cows: Balancing physically effective fiber with starch availability. Pages 16-27 in Proc. Florida Ruminant Nutrition Symp., Gainesville, FL. University of Florida, Gainesville.

Beauchemin, K. A., L. Eriksen, P. Nørgaard, and L. M. Rode. 2008. Short communication: Salivary secretion during meals in lactating dairy cattle. J. Dairy Sci. 91:2077-2081. https://doi.org/10.3168/ jds.2007-0726.

Bielharz, R. G., and K. Zeeb. 1982. Social dominance in dairy cattle. Appl. Anim. Ethol. 8:79-97. https://doi.org/10.1016/03043762(82)90134-1.

CCAC. 2009. Guidelines on: The Care and Use of Farm Animals in Research, Teaching and Testing. Canadian Council on Animal Care, Ottawa, ON, Canada.

Chapinal, N., D. M. Veira, D. M. Weary, and M. A. G. von Keyserlingk. 2007. Technical note: Validation of a system for monitoring individual feeding and drinking behavior and intake in group housed dairy cows. J. Dairy Sci. 90:5732-5736. https://doi. org/10.3168/jds.2007-0331.

Cook, N. B., K. V. Nordlund, and G. R. Oetzel. 2004. Environmental influences on claw horn lesions associated with laminitis and sub-acute ruminal acidosis (SARA) in dairy cows. J. Dairy Sci. 87(E. Suppl.):E36-E46. https://doi.org/10.3168/jds.S00220302(04)70059-4.

Dado, R. G., and M. S. Allen. 1994. Nutrition, feeding, and calves. Variation in and relationships among feeding, chewing, and drinking variables for lactating dairy cows. J. Dairy Sci. 77:132-144. https://doi.org/10.3168/jds.S0022-0302(94)76936-8.

DeVries, T. J., K. A. Beauchemin, and M. A. G. von Keyserlingk. 2007. Dietary forage concentration affects the feed sorting behavior of lactating dairy cows. J. Dairy Sci. 90:5572-5579. https://doi. org/10.3168/jds.2007-0370.

DeVries, T. J., F. Dohme, and K. A. Beauchemin. 2008. Repeated ruminal acidosis challenges in lactating dairy cows at high and low risk for developing acidosis: Feed sorting. J. Dairy Sci. 91:3958 3967. https://doi.org/10.3168/jds.2008-1264.

DeVries, T. J., and M. A. G. von Keyserlingk. 2005. Time of feed delivery affects the feeding and lying patterns of dairy cows.
J. Dairy Sci. 88:625-631. https://doi.org/10.3168/jds.S00220302(05) 72726-0.

DeVries, T. J., and M. A. G. von Keyserlingk. 2006. Feed stalls affect the social and feeding behavior of lactating dairy cows. J. Dairy Sci. 89:3522-3531. https://doi.org/10.3168/jds.S00220302(06)72392-X.

DeVries, T. J., M. A. G. von Keyserlingk, and K. A. Beauchemin. 2003a. Short communication: Diurnal feeding pattern of lactating dairy cows. J. Dairy Sci. 86:4079-4082. https://doi.org/10.3168/ jds.S0022-0302(03)74020-X.

DeVries, T. J., M. A. G. von Keyserlingk, and D. M. Weary. 2004. Effect of feeding space on the inter-cow distance, aggression, and feeding behavior of free-stall housed lactating dairy cows. J. Dairy Sci. 87:1432-1438. https://doi.org/10.3168/jds.S00220302(04)73293-2.

DeVries, T. J., M. A. G. von Keyserlingk, D. M. Weary, and K. A. Beauchemin. 2003b. Measuring the feeding behavior of lactating dairy cows in early to peak lactation. J. Dairy Sci. 86:3354-3361. https://doi.org/10.3168/jds.S0022-0302(03)73938-1.

Galindo, F. and D. M. Broom. 2000. The relationships between social behaviour of dairy cows and the occurrence of lameness in three herds. Res. Vet. Sci. 69:75-79. https://doi.org/10.1053/ rvsc.2000.0391.

Giraldeau, L. A., and T. Caraco. 2000. Social Foraging Theory. Princeton University Press, Princeton, NJ.

Grant, R. J., and J. L. Albright. 2001. Effect of animal grouping on feeding behavior and intake of dairy cattle. J. Dairy Sci 84(E. Suppl.):E156-E163. https://doi.org/10.3168/jds.S00220302(01)70210-X.

Greenough, P. R., and J. J. Vermunt. 1991. Evaluation of subclinical laminitis in a dairy herd and observations on associated nutritional and management factors. Vet. Rec. 128:11-17. https://doi. org/10.1136/vr.128.1.11

Hart, K. D., B. W. McBride, T. F. Duffield, and T. J. DeVries. 2013. Effect of milking frequency on the behavior and productivity of lactating dairy cows. J. Dairy Sci. 96:6973-6985. https://doi. org/10.3168/jds.2013-6764.

Hart, K. D., B. W. McBride, T. F. Duffield, and T. J. DeVries. 2014 Effect of frequency of feed delivery on the behavior and productivity of lactating dairy cows. J. Dairy Sci. 97:1713-1724. https://doi. org/10.3168/jds.2013-7504.

Hetti Arachchige, A. D., A. D. Fisher, W. J. Wales, M. J. Auldist, M. C. Hannah, and E. C. Jongman. 2014. Space allowance and barriers influence cow competition for mixed rations fed on a feed-pad between bouts of grazing. J. Dairy Sci. 97:3578-3588. https://doi. org/10.3168/jds.2013-7553.

Hosseinkhani, A., T. J. DeVries, K. L. Proudfoot, R. Valizadeh, D. M. Veira, and M. A. G. von Keyserlingk. 2008. The effects of feed bunk competition on the feed sorting behavior of close-up dry cows. J. Dairy Sci. 91:1115-1121. https://doi.org/10.3168/ jds.2007-0679.

Huzzey, J. M., T. J. DeVries, P. Valois, and M. A. G. von Keyserlingk. 2006. Stocking density and feed barrier design affect the feeding and social behavior of dairy cattle. J. Dairy Sci. 89:126-133. https://doi.org/10.3168/jds.S0022-0302(06)72075-6.

Huzzey, J. M., R. J. Grant, and T. R. Overton. 2012a. Short communication: Relationship between competitive success during displacements at an overstocked feed bunk and measures of physiology and behavior in Holstein dairy cattle. J. Dairy Sci. 95:4434-4441. https://doi.org/10.3168/jds.2011-5038.

Huzzey, J. M., D. V. Nydam, R. J. Grant, and T. R. Overton. 2012b. The effects of overstocking Holstein dairy cattle during the dry period on cortisol secretion and energy metabolism. J. Dairy Sci. 95:4421-4433. https://doi.org/10.3168/jds.2011-5037.

Huzzey, J. M., D. M. Weary, B. Y. F. Tiau, and M. A. G. von Keyserlingk. 2014. Short communication: Automatic detection of social competition using an electronic feeding system. J. Dairy Sci. 97:2953-2958. https://doi.org/10.3168/jds.2013-7434.

King, M. T. M., R. E. Crossley, and T. J. DeVries. 2016. Impact of timing of feed delivery on the behavior and productivity of 
dairy cows. J. Dairy Sci. 99:1471-1482. https://doi.org/10.3168/ jds.2015-9790.

Kononoff, P. J., A. J. Heinrichs, and D. R. Buckmaster. 2003. Modification of Penn State forage and total mixed ration particle separator and the effects of moisture content on its measurement. J. Dairy Sci. 86:1858-1863.

Krause, K. M., and G. R. Oetzel. 2006. Understanding and preventing subacute ruminal acidosis in dairy herds: A review. Anim. Feed Sci. Technol. 126:215-236. https://doi.org/10.1016/j. anifeedsci.2005.08.004.

Ledgerwood, D. N., C. Winckler, and C. B. Tucker. 2010. Evaluation of data loggers, sampling intervals, and editing techniques for measuring the lying behavior of dairy cattle. J. Dairy Sci. 93:51295139. https://doi.org/10.3168/jds.2009-2945.

Lee, J., J. Seo, S. Y. Lee, K. S. Ki, and S. Seo. 2014. Meta-analysis of factors affecting milk component yields in dairy cattle. J. Anim. Sci. Technol. 56:5. https://doi.org/10.1186/2055-0391-56-5.

Leonardi, C., and L. E. Armentano. 2003. Effect of quantity, quality, and length of alfalfa hay on selective consumption by dairy cows. J. Dairy Sci. 86:557-564. https://doi.org/10.3168/jds.S00220302(03)73634-0.

MacDonald, P. D. M., and P. E. J. Green. 1988. User's Guide to Program MIX: An Interactive Program for Fitting Mixtures of Distributions. Release 2.3, January 1988. Ichthus Data Systems, Hamilton, ON, Canada.

Maekawa, M., K. A. Beauchemin, and D. A. Christensen. 2002. Effect of concentrate level and feeding management on chewing activities, saliva production, and ruminal $\mathrm{pH}$ of lactating dairy cows. J. Dairy Sci. 85:1165-1175. https://doi.org/10.3168/jds.S00220302(02)74179-9.

Miller-Cushon, E. K., and T. J. DeVries. 2010. Feeding amount affects the sorting behavior of lactating dairy cows. Can. J. Anim. Sci. 90:1-7. https://doi.org/10.4141/CJAS09047

Morris, T. R. 1999. Experimental Design and Analysis in Animal Sciences. CABI Publishing, New York, NY.

Munksgaard, L., M. B. Jensen, L. J. Pedersen, S. W. Hansen, and L. Matthews. 2005. Quantifying behavioural priorities - effects of time constraints on behaviour of dairy cows, Bos taurus. Appl. Anim. Behav. Sci. 92:3-14. https://doi.org/10.1016/j. applanim.2004.11.005.
Nielsen, B. L. 1999. On the interpretation of feeding behaviour measures and the use of feeding rate as an indicator of social constraint. Appl. Anim. Behav. Sci. 63:79-91. https://doi.org/10.1016/S01681591(99)00003-9.

NRC. 2001. Nutrient Requirements for Dairy Cattle. Natl. Acad. Sci., Washington, DC.

Olofsson, J. 1999. Competition for total mixed diets fed for ad libitum intake using one or four cows per feeding station. J. Dairy Sci 82:69-79. https://doi.org/10.3168/jds.S0022-0302(99)75210-0.

Proudfoot, K. L., D. M. Veira, D. M. Weary, and M. A. G. von Keyserlingk. 2009. Competition at the feed bunk changes the feeding, standing, and social behavior of transition dairy cows. J. Dairy Sci. 92:3116-3123. https://doi.org/10.3168/jds.2008-1718.

Rioja-Lang, F. C., D. J. Roberts, S. D. Healy, A. B. Lawrence, and M. J. Haskell. 2009. Dairy cows trade-off feed quality with proximity to a dominant individual in Y-maze choice tests. Appl. Anim. Behav. Sci. 117:159-164. https://doi.org/10.1016/j.applanim.2008.12.003.

SAS Institute Inc. 2013. SAS version 9.4. SAS Institute Inc., Cary, NC.

Schirmann, K., M. A. G. von Keyserlingk, D. M. Weary, D. M. Veira, and W. Heuwieser. 2009. Technical note: Validation of a system for monitoring rumination in dairy cows. J. Dairy Sci. 92:6052-6055. https://doi.org/10.3168/jds.2009-2361.

Shabi, Z., M. R. Murphy, and U. Moallem. 2005. Within-day feeding behavior of lactating dairy cows measured using a real-time control system. J. Dairy Sci. 88:1848-1854.

Shaver, R. D. 2002. Rumen acidosis in dairy cattle: Bunk management considerations. Adv. Dairy Technol. 14:241-249.

Tyrrell, H. F., and J. T. Reid. 1965. Prediction of the energy value of cow's milk. J. Dairy Sci. 48:1215-1223. https://doi.org/10.3168/ jds.S0022-0302(65)88430-2.

Val-Laillet, D., A. M. D. Passillé, J. Rushen, and M. A. G. von Keyserlingk. 2008. The concept of social dominance and the social distribution of feeding-related displacements between cows. Appl. Anim. Behav. Sci. 111:158-172. https://doi.org/10.1016/j. applanim.2007.06.001.

Van Soest, P. J. J. B. Robertson, and B. A. Lewis, 1991. Methods for dietary fiber, neutral detergent fiber and nonstarch polysaccharide in relation to animal nutrition. J. Dairy Sci. 74:3583-3597. https://doi.org/10.3168/jds.S0022-0302(91)78551-2. 